\title{
A LAICIDADE COMO UM PROBLEMA DE GÊNERO NO BRASIL: DEBATES NO TWITTER
}

\author{
Emilly Joyce Oliveira Lopes Silva* \\ Luciana Patrícia Zucco**
}

\section{RESUMO}

Este trabalho analisou o conceito de laicidade e suas especificidades no Brasil, a partir de uma perspectiva de gênero, tendo o Twitter como cenário de coleta de dados. Optamos por tratar, incialmente, da discussão em torno da categoria gênero. Em seguida, apresentamos como o cristianismo participa da história das relações de gênero, constituindo um padrão de ser/agir. O passo seguinte foi apresentar o conceito de laicidade e os arranjos do Estado laico no Brasil desde seu aparecimento na Constituição de 1891. Por fim, observamos, por meio da cartografia, o debate em torno desses temas no site Twitter. Com esta análise, fica explícito que o argumento da "ideologia de gênero" é um recurso discursivo religioso contra a desconstrução das diferenças entre homens e mulheres.

Palavras-chave: Laicidade. Cristianismo. Gênero.

\section{SECULARISM AS A GENDER TROUBLE IN BRAZIL: TWITTER DISCUSSIONS}

\section{ABSTRACT}

This paper aims to analyze the concept of secularity and its specificities in Brazil from a gender perspective. In this sense, we have chosen to deal initially with the discussion about the gender category. Next, we seek to show how Christianity participate in the history of gender relations, constituting a pattern of being / acting. The next step was

* Doutoranda Interdisciplinar em Ciências Humanas na Universidade Federal de Santa Catarina (UFSC). Mestra em História pela Universidade Federal de Minas Gerais (UFMG). Graduada em História pela Universidade Federal de Minas Gerais (UFMG).

** Professora Associada do Programa de Pós-Graduação em Serviço Social da Universidade Federal de Santa Catarina. Doutora em Ciências da Saúde pelo Instituto Fernandes Figueira (IFF), Fundação Oswaldo Cruz (FIOCRUZ). Integrante do Núcleo de Estudos em Serviço Social e Relações de Gênero (NUSSERGE/UFSC) e do Instituto de Estudos de Gênero (IEG/UFSC). 
to present the concept of secularism and the lay State arrangements in Brazil since its appearance in the 1891's Constitution. Finally, we observe, through cartography, the debate around these themes on the Twitter site. With this analysis, it's explicit that the argument of "gender ideology" is a religious discursive resource against the deconstruction of differences between men and women.

Keywords: Secularism. Christianity. Gender.

\section{LA LAICIDAD COMO UN PROBLEMA DE GÉNERO EN BRASIL: DEBATES EN TWITTER}

\section{RESUMEN}

Este artículo pretende analizar el concepto de secularidad y sus especificidades en Brasil desde una perspectiva de género. En este sentido, hemos optado por tratar inicialmente con la discusión sobre la categoría "género". A continuación, buscamos mostrar cómo la religión cristiana participa en la historia de las relaciones de género, constituyendo un patrón de ser / actuar. El siguiente paso fue presentar el concepto de laicidad y los arreglos del Estado laico en Brasil desde su aparición en la Constitución de 1891. Finalmente, observamos, a través de la cartografía, el debate en torno a estos temas en el sitio de Twitter. Con este análisis, es explícito que el argumento de es un recurso religioso discursivo contra la deconstrucción de las diferencias entre hombres y mujeres.

Palabras clave: Laicidad. Cristianismo. Género.

\section{INTRODUÇÃO}

É preciso dizer, antes de tudo, que este artigo não se organiza do mesmo modo como se deu o trabalho de coleta de dados. Aqui, a teoria vem primeiro, servindo de base para a compreensão do que identificamos no campo, porém foi o próprio campo que ditou as escolhas teóricas.

O Twitter foi cenário de coleta de dados e visibilizou o debate em torno da laicidade, a partir do método cartográfico. A partir da cartografia, acompanhamos as postagens feitas no Twitter relacionadas à categoria gênero e sua relação com a religião, bem como, com o conceito de laicidade. Liliana da Escóssia, Virgínia Kastrup e Eduardo Passos afirmam que o sentido da cartografia envolve "acompanhamento de 
percursos, implicação em processos de produção, conexão de redes ou rizomas" (Liliana ESCÓSSIA; Virgínia, KASTRUP; Eduardo PASSOS, 2012, p. 13). Ademais, as/os autoras/es abordam a cartografia como inversão do método, uma vez que, na origem da palavra (metá + hódos), o sentido é de um caminho (hodós) indicado pelas metas.

As questões relacionadas a gênero apareceram com grande frequência nas postagens que defendem ou se opõem ao Estado laico. Esse "emaranhado" de posições explicitou um tensionamento entre religiões, espaço público, ruptura com padrões morais e maior liberdade individual, possibilitando analisar o conceito de laicidade e suas especificidades no Brasil, a partir de uma perspectiva de gênero.

Iniciamos o artigo com uma breve introdução aos estudos sobre a categoria gênero. Em seguida, relacionamos os estudos de gênero com as religiões cristãs, e mostramos como essas contribuíram para instituir padrões de homem/masculinidade e mulher/feminilidade em nossa sociedade. Por fim, apresentamos a discussão dos dados, trazendo postagens ligadas à temática.

\section{ENTRELAÇAMENTO ENTRE GÊNERO E RELIGIÃO}

A partir de Linda Nicholson (2000), tomamos gênero, assim como sexo, como construções sociais, históricas e culturais. A autora chama a atenção para os usos contraditórios da palavra gênero. Se por um lado remete à oposição ao sexo, tomado em seu uso corrente como dado biológico, por outro é utilizado para fazer a distinção entre corpos femininos e masculinos. Logo, o segundo modo de ver se opõe ao primeiro, porque entende o corpo também como construção. Para a autora: "Se o próprio corpo é sempre visto através de uma interpretação social, então o "sexo" não pode ser independente do "gênero"; antes, sexo nesse sentido deve ser algo que possa ser subsumido pelo gênero" (Linda NICHOLSON, 2000, p. 10).

Linda Nicholson (2000) irá problematizar a dicotomia sexo-gênero. Em outras palavras, poderíamos dizer que o corpo é natureza e cultura, não havendo essa separação clara a que muitos/as autores/as recorrem. Afirma que muitas feministas não romperam com os determinismos biológicos e utilizaram as supostas diferenças entre homens e mulheres 
conforme suas conveniências: negando-as quando prejudiciais ao feminismo, mas, simultaneamente, aproveitando algumas vantagens desse modelo de interpretação. Nesse sentido, o grande acréscimo trazido por sua análise é a complexificação do conceito, que possibilita problematizar o termo "mulher" e compreendê-lo a partir de uma rede imbricada de características que não podem ser reduzidas a um corpo biologizado.

O trabalho de Linda Nicholson dialoga diretamente com o pensamento de Thomas Laqueur (2001). O autor discorre sobre como a diferença biológica entre homens e mulheres foi construída a partir do século XVII. Segundo ele, ocorre, nesse período, uma mudança do modelo do sexo único, ancorado na inversão do órgão reprodutor masculino nas mulheres, para o modelo dos dois sexos, como conhecemos na atualidade. Ao fazer essa historicização, ressalta que a diferenciação entre corpos masculinos e femininos se dá por motivações políticas, muito mais do que pelo conhecimento biológico que se tinha à época. Ele afirma, ainda, que até o século XVII o sexo não era considerado uma categoria ontológica, ou seja, algo fundante para a existência. Assim, o sexo estaria envolvido em uma dimensão relacional, sendo, portanto, tão construído quanto a identidade de gênero.

As construções ancoradas nas identidades de gênero não são aleatórias. Elas se constroem conforme regras sociais bastante rígidas, nas quais os "desvios" não são "bem-vindos". Em termos gerais, podemos dizer que há "o que se espera de um homem" e "o que se espera de uma mulher", e esse horizonte de expectativas se relaciona diretamente com o debate de gênero. Judith Butler (2003) fala de uma matriz cultural que define identidades que podem ou não existir. As identidades aceitas são aquelas em que sexo e gênero correspondem, bem como, as práticas do desejo decorrem dessa ligação. Relaciona as normas de gênero à heterossexualidade, uma vez que tanto a feminilidade quanto a masculinidade idealizadas se pautam pela matriz heterossexual. Segundo Judith Butler, é possível dizer que a heterossexualidade opera por meio da produção regulada de versões hiperbólicas de homem e mulher (Judith BUTLER, 2002). O que não corresponde a essa matriz é entendido, portanto, como falha, ainda que de fato não existam indivíduos capazes de corresponder a essas exigências. 
Outro ponto importante do debate sobre o conceito de gênero é sua relação com a política. Aqui, nos interessa, sobretudo, a definição de Joan Scott (1990), que coloca o gênero como estruturante para as relações de poder. Para a autora, ainda que existam diferenças biológicas entre os corpos, o que interessa são as construções histórico-culturais que delimitam e hierarquizam os corpos. Influenciada pelos pós-estruturalistas, a historiadora critica a forma rígida e essencialista como o marxismo, a psicanálise e as teorias do patriarcado compreenderam as identidades de gênero. Recuperando Foucault, ela insiste em uma definição de gênero que é, ao mesmo tempo, histórica e política, centrada nas relações de poder. Segundo ela: "O gênero é um elemento constitutivo de relações sociais fundadas sobre as diferenças percebidas entre os sexos, e o gênero é o primeiro modo de dar significado às relações de poder" (Joan SCOTT, 1990, p. 14).

Nesse sentido, tal debate nos leva a pensar de que modo as religiões contribuem para as construções históricas e culturais que diferenciam os corpos. Entendemos que aspecto religioso ocupa um lugar central para as identidades de gênero, uma vez que as normas culturais do "ser homem" e do "ser mulher" integram os referenciais morais e teológicos nos quais se baseiam diversos grupos cristãos.

O livro de Uta Ranke-Hainemann, intitulado Eunucos pelo reino de Deus: mulheres, sexualidade e a igreja católica (1996), é um dos principais estudos a pensar o modo como a teologia católica se posicionou em relação à sexualidade, aos prazeres e às mulheres. No que diz respeito a estas, o argumento principal da autora é de que a hostilidade de Jesus Cristo aos prazeres, conforme o que se interpreta da Bíblia Sagrada, teria desvalorizado as mulheres, assim como, boa parte das pessoas comuns:

A hostilidade de Jesus ao prazer também teve consequências para a imagem que os teólogos faziam das demais mulheres. A imagem que oferecem é de inferioridade. Só servem para ter filhos, a menos que dediquem à auto-santificação, como fazem as virgens. Mas não se pode fazer filhos sem fazer sexo e sem a mulher ser "maculada pela presença do sêmen masculino". Assim, a hostilidade de Jesus ao prazer significou que o desfrute do prazer sexual seria excluído do casamento cristão, tanto quanto possível, e muitas vezes sujeito a ameaças de condenação eterna (Uta RANKE-HEINEMANN, 1996, p. 17). 
Recorrendo a um profundo conhecimento da Teologia, Uta Ranke-Heinamann (1996) mostra como a prática da homossexualidade, do aborto, da contracepção e da masturbação (onanismo) foram condenadas pela Igreja Católica no decorrer da História. Em sua análise, a autora mostra, ainda, como os escolásticos, principalmente Agostinho e seus seguidores Alberto Magno e Tomás de Aquino, foram grandes responsáveis pela propagação de uma visão da mulher como ser inferior. Ela aponta o século XIII como "apogeu da difamação misógina", reforçando que a demonização do sexo e a noção de mulher como "homem mal gerado ou deficiente"1 (Uta RANKE-HEINEMANN, 1996, p. 199) ganharam força nesse momento, repercutindo até o século XX. Citando Elizabete Bicalho (2001):

A misoginia, ou seja, a aversão para com a mulher e a tudo que venha dela, a visão da mulher como portadora do mal e o temor com relação às mulheres, não nasce com o cristianismo, mas é incorporada no pensamento cristão e percorrerá séculos na história humana, constituindo-se como elemento formador da suposta inferioridade feminina. O pensamento misógino justifica práticas culturais e relações intersubjetivas na assimetria entre o masculino e o feminino, desenvolvendo sentimentos de inferioridade e culpabilidade na mulher. (...) Toda a simbologia que nos fala da expulsão do homem e da mulher do paraíso traz para a humanidade a perda da condição divina e essencialmente para a mulher, a nódoa do pecado, porque foi ela que se entregou ao demônio. Pecadora, ela terá de se redimir na submissão e resignação (Elizabete BICALHO, 2001, p. 17).

Nesse sentido, o ideário teológico que fundamenta o cristianismo ocupa lugar de destaque na construção de uma "matriz cultural", para usar o termo de Judith Butler (2003), que inferioriza mulheres, diferencia corpos e condena o prazer. Isso não significa, contudo, que todos os grupos cristãos se alinham com esse ideário. Maria José Rosado-Nunes (2015) lembra que a religião tem um caráter ambíguo em sua relação

Essa visão não foi recebida sem críticas, segundo Uta Ranke-Heinemann. Guilherme de Alvergne lembrou que, ao falar que a mulher é um homem malformado, pode-se entender que o homem seria, então, uma mulher perfeita, algo não muito interessante para uma igreja que também condenava a homossexualidade. 
com as questões de gênero. Segundo ela, "as religiões não funcionam sempre e em todas as sociedades como forças conservadoras que contribuem para a subordinação de mulheres" (Maria José ROSADO-NUNES, 2015, p. 10), ou seja, podem possibilitar a emancipação e mudanças no âmbito do espaço religioso. Ainda assim, a autora reconhece que, na condição de fieis, essas mulheres também se submetem ao "poder disciplinador das religiões” (Maria José ROSADO-NUNES, 2015, p. 10).

Com base nessa discussão, defendemos aqui a hipótese de que as religiões contribuem, de maneira decisiva, para uma matriz cultural que impõe normas e limites aos corpos, desejos e vivências das pessoas. Por isso, a laicidade desponta como uma importante demanda dos movimentos feministas, LGBTs e demais grupos preocupados com a igualdade e emancipação, principalmente, de gênero.

\section{LAICIDADE E ARRANJOS DO ESTADO LAICO BRASILEIRO}

Diversos assuntos controversos, como o ensino religioso nas escolas, a criminalização do aborto (PEC 181/2011), a retirada do tema sexualidade e gênero ("ideologia de gênero") da política de educação, e a união civil entre casais homoafetivos, são discutidos pela população e representantes políticos por meio do crivo da religião. Ao mesmo tempo, a laicidade do Estado brasileiro, garantida pela Constituição de $1988,{ }^{2}$ aparece como contraponto aos argumentos religiosos. Na prática, o que se observa são diferentes arranjos e embates que caracterizam a relação entre o religioso e o político em nossa sociedade.

A maior parte das pessoas reconhece a separação entre Estado e religião. Porém, o conceito de laicidade é mais complexo do que costumamos imaginar. De acordo com Fernando Catroga (2006), toda laicidade é uma secularização, mas nem toda secularização é ou foi uma laicidade. O cerne da diferenciação estaria na existência de um "sujeito ativo" para a implementação da laicidade. Ela é entendida como um fenômeno político muito mais que um problema da ordem das religiões.

O artigo 5 inciso VI da Constituição Brasileira de 1988 garante a liberdade de culto, a liberdade de crença e a liberdade de organização religiosa. Já no artigo 19, inciso I, fica expressa a não participação do Estado em qualquer forma de culto ou organização religiosa (Túlio VIANNA, 2014). 
De forma geral, o conceito pode ser definido como "exclusão ou ausência da religião na esfera pública" (Carlos RANQUETAT JÚNIOR, 2008, p. 5). A laicidade implicaria, com isso, uma certa "neutralidade do Estado em matéria religiosa" (Carlos RANQUETAT JÚNIOR, 2008, p. 6), apresentando-se de duas formas: na imparcialidade do Estado em relação às religiões, obrigando-o a tratar com igualdade todos os credos; e na retirada do poder religioso do Estado.

A relação entre Estado laico e democracia é fundamental. Para que o Estado possa representar todos/as os/as cidadãos/ãs de forma equânime é necessário que se coloque em uma posição distanciada das religiões, para garantir a liberdade de culto às mais diversas formas de doutrina. Segundo Roberto Blancarte (2008), a laicidade é, portanto, um regime de convivência social, cujas instituições políticas estão legitimadas principalmente pela soberania popular e não mais elementos religiosos. De acordo com o pesquisador, o mais importante é acentuar a laicidade como um processo e não como algo estanque, definido, não mutável, sendo impossível afirmar que determinado Estado seja plenamente laico. Trata-se, desse modo, de um terreno em constante disputa, atravessado por diferentes interesses.

No caso do Brasil, o catolicismo foi a religião oficial durante boa parte de nossa história, devido à imposição portuguesa durante o processo de colonização. Somente com a primeira constituição republicana, datada de 1891, o Estado se tornou independente da Igreja Católica, possibilitando que outras religiões pudessem realizar seus cultos e rituais de forma livre. Até hoje, contudo, há uma forte relação entre o cristianismo (englobando o catolicismo e as igrejas protestantes) e o Estado.

Segundo Emerson Giumbelli, o cenário brasileiro, no que diz respeito à laicidade, caracteriza-se por "vínculos, compromissos, contatos, cumplicidades entre autoridades e aparatos estatais e representantes e instituições católicas" (Emerson GIUMBELLI, 2002, p. 155). Ele afirma, ainda, a existência de um esquema de "colaboração" entre o Estado e as religiões cristãs - em alguns casos, como nas instituições de saúde, o espiritismo também é incluído. Por outro lado, diversos tipos de culto, como os de religiões de matriz africana, nem sempre são considerados, para fins legais, como uma instituição religiosa detentora de direitos (e deveres). 
A laicidade, segundo Roberto Blancarte (2012), sustenta-se em três pilares: 1) no respeito à liberdade de consciência; 2) na autonomia do político em relação ao religioso; 3) na garantia à igualdade e na não discriminação. Ao observamos o processo brasileiro, podemos perceber que o respeito à liberdade de consciência existe, mas quase sempre limitado àqueles que manifestam a fé cristã, de modo semelhante ao que acontece com a garantia à igualdade e à não discriminação. $A$ autonomia do político frente ao religioso é garantida pela Constituição, mas esbarra em uma forte tradição católica e na estratégia, sobretudo dos neopentecostais, de ocupar os cargos políticos. Dessa maneira, muitas das decisões políticas são pautadas por valores religiosos que não correspondem aos princípios da liberdade e da igualdade.

\section{NO TWITTER: O DEBATE SOBRE GÊNERO, LAICIDADE E RELIGIÃO}

No processo cartográfico, os caminhos é que apontariam as metas, ou seja, é por meio da experimentação do terreno que surgem as próprias definições da pesquisa. Eles defendem a existência de pistas: "As pistas que guiam o cartógrafo são como referências que concorrem para manutenção de uma atitude de abertura ao que vai se produzindo e de calibragem do caminhar no próprio percurso da pesquisa - o hódos-metá da pesquisa" (Liliana ESCÓSSIA; Virgínia, KASTRUP; Eduardo PASSOS, 2012, p. 13).

Para esta cartografia, optamos por três combinações de palavras-chave que foram usadas no campo de pesquisa do Twitter: 1) Estado-laico e mulher; 2) Estado-laico e mulheres; 3) laicidade e gênero. 0 recorte temporal foi delimitado pelo presente ano, sendo as postagens analisadas entre janeiro e julho de 2017, da recente para a mais antiga, conforme a organização do próprio site. A composição do corpus se deu mediante a identificação das postagens com o emprego das palavras-chave. A tabela a seguir resume os dados coletados: 


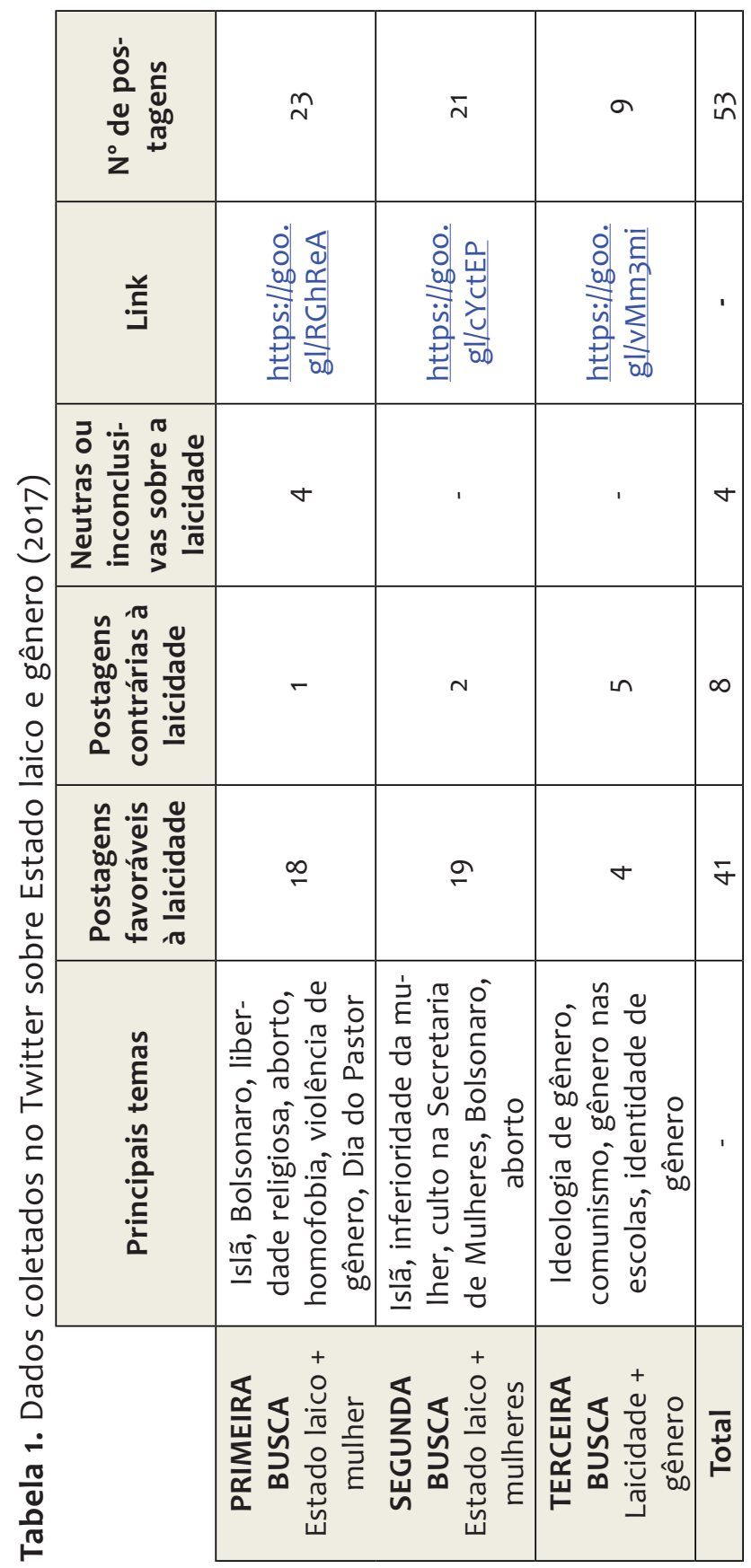


Na tabela, colocamos os principais dados coletados em nossas buscas no Twitter. No total, foram analisadas 53 postagens. Os Principais Temas incluem tags que apareceram com frequência nas postagens; as colunas relativas às Postagens Contrárias, Favoráveis, Neutras ou Inconclusivas dizem respeito à questão da laicidade; os links dão acesso às páginas da busca, a fim de verificação dos dados explicitados aqui.

Com base nesse levantamento geral, seguimos as pistas oferecidas pelo campo. Dessa forma, algumas postagens, mais representativas, foram analisadas aprofundadamente. Nesses casos, fizemos o print do comentário, omitindo o nome de usuário do/da autor/a. Eventualmente, abrimos os links que acompanhavam as postagens caso parecessem acrescentar pontos interessantes ao debate, ou seja, estavam diretamente relacionados ao objeto da pesquisa. Consideramos, igualmente, outras postagens voltadas à temática ou o perfil de quem as postava, a fim de compreender melhor o que estava escrito/inscrito naqueles 140 caracteres - limite de tamanho nas postagens do Twitter até julho de 2017.

De um modo geral, os dados coletados (Tabela 1) nos permitiram observar que o debate contemporâneo no Brasil de temas com apelo religioso tende a uma polarização, que resume o debate em "contra" e "a favor". De um lado estão as/os defensora/es do Estado laico, quase sempre identificadas/os com demandas políticas de esquerda. Do outro, aquelas/es que não desejam interferência em quesitos religiosos, em alguns casos, associando a laicidade ao comunismo e à "ideologia de gênero". Em nosso levantamento, notamos que a maioria dos comentários é favorável ao Estado laico, ainda que flexibilizem seu conteúdo. Os posicionamentos contrários quase sempre associam laicidade à ideologia de gênero (Figuras 1, 6 e 7).

Um dos argumentos mais interessantes é apresentado por um/a usuário/a que defende a liberdade religiosa como equivalente de laicidade (Figura 1), sendo possível recuperar o pensamento de Roberto Blancarte (2012). Para o autor, o Estado laico incorpora dois aspectos de igual importância: tratar com equidade toda e qualquer religião; garantir que essas religiões não interfiram diretamente nas políticas do Estado. A postagem dá a entender que não é um problema os políticos falarem de Deus em seus discursos, porque a laicidade corresponde à igualdade. 


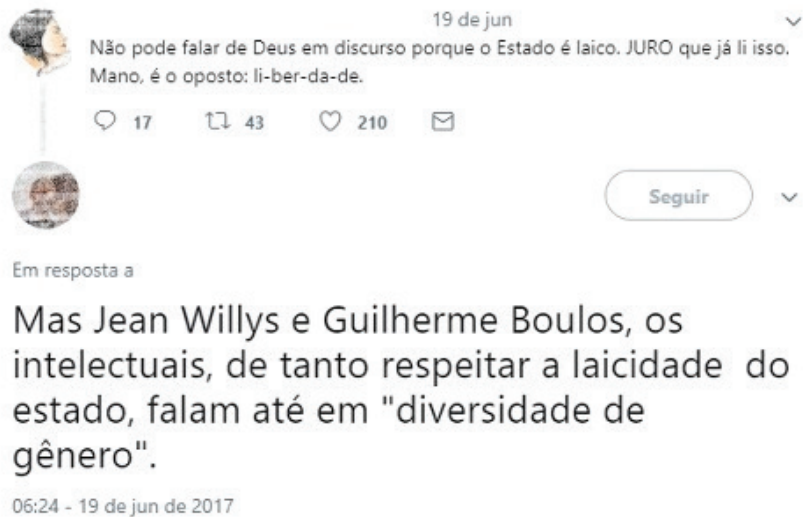

$06: 24$ - 19 de jun de 2017

Figura 1. Definição de laicidade como liberdade

Aqui se explicita um dos pontos mais complexos do debate em torno do Estado laico: como fica o posicionamento individual dos políticos em questões de fé quando esses se tornam homens públicos? A recente votação para impeachment da presidenta Dilma ressaltou esse nó quando centenas de votos foram feitos em nome de Deus. Em um Estado efetivamente laico, esse comportamento seria aceitável? Parece-nos que votar em nome de qualquer divindade não é exatamente um problema político, mas trata-se de um ato com enorme valor simbólico. Esses mesmos/as deputados/as não colocariam sua fé acima das questões públicas quando fossem votar projetos de lei? Não podemos, portanto, restringir a laicidade ao aspecto da liberdade religiosa. É preciso lembrar que a não interferência das religiões em assuntos públicos é uma forma de preservar essa liberdade e garantir que todos estejam protegidos pela Constituição.

Outro dado interessante desse emaranhado é identificado em uma postagem que trata claramente da "imagem pintada", por muitas religiões, sobre as mulheres como um ser inferior: 
Figura 2. Inferioridade da mulher nas religiões

Essa constatação remete ao argumento de Uta Ranke-Heinemann (1996) sobre o modo como o catolicismo lidou com as mulheres e sua sexualidade. Além disso, está explícito o respeito às religiões: como respeitar essas instituições quando não há reciprocidade? A partir do momento em que as igrejas interferem nas liberdades individuais, impondo seus padrões morais, é possível realmente haver respeito/ tolerância? A questão não tem uma resposta simples, mas revela que, na prática, os princípios da liberdade religiosa e da não interferência das religiões no Estado não se coadunam facilmente. Nesse sentido, há uma fragilidade da democracia no que tange à laicidade, algo complexo de se solucionar, mas que não pode deixar de ser pensado.

A legalização do aborto foi mais um tema recorrente nas postagens. Esse talvez seja um dos pontos centrais com relação às palavras-chave utilizadas: de um lado, o direito à interrupção voluntária da gravidez é uma demanda consolidada dos movimentos feministas em todo o mundo (Tamara GONÇALVES; Thaís LAPA, 2008); do outro, há uma forte contrapartida de grupos religiosos, defensores do direito à vida. No debate sobre laicidade no Twitter, essa tensão aparece em diferentes postagens:

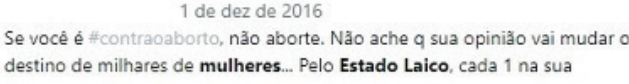

Q 七า

Figura 3. Aborto e Estado laico 
Sou católica e como a minha religiåo sou contra $+n$ posso impor as vontade da minha religião em um estado laico e nem no utero de uma mulher

Anjo do Fake@anjodofk

Em resposta a @anjodofk

1. Qual é a sua opiniăo sobre o aborto? Quem decide um aborto?

○ ᄂา $1 \quad 01 \quad \square$

Figura 4. Católica favorável à legalização do aborto

- 6 de jul

Estão em jogo vida, saúde das mulheres, e o princípio do Estado laico, básico

para que haja esperança de democracia.

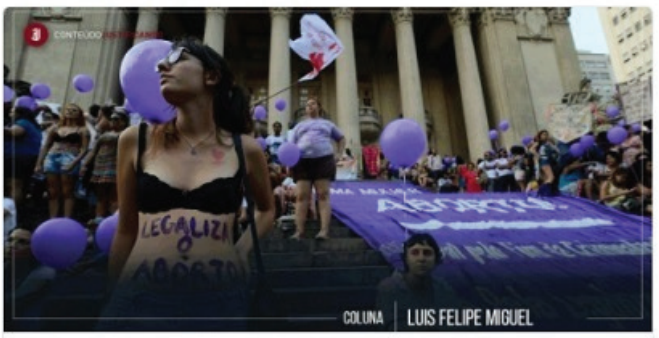

Sem direito ao aborto, não há cidadania para as mulheres

Foto: Femando Frazão/Agência Brasil Em meio a tantos ataques à

cidadania, que fazem a conjuntura brasileira parecer um campo de guerra,

justificando cartacapital com. br

$Q 7 \quad$ โว $28 \quad \bigcirc_{38} \quad \square$

Figura 5. Notícia sobre direito ao aborto e cidadania

A postagem da Figura 3 recorre a um dos argumentos mais comuns para a legalização do aborto: no Estado laico, todos têm o direito de agir conforme sua própria consciência. Essa opinião pode corresponder ao pensamento de grande parte da população. Em abril de 2017, o grupo "Católicas pelo Direito de Decidir" (CDD) divulgou uma pesquisa sobre a legalização do aborto no Brasil.3 O levantamento foi realizado pelo IBOPE Inteligência, que ouviu duas mil pessoas em 143 municípios durante o mês de fevereiro do presente ano. Foram ouvidos homens e mulheres com idade entre 16 e 65 anos.

3 Os dados da pesquisa podem ser consultados aqui:

http://www.correiobraziliense.com.br/app/noticia/brasil/2017/04/04/internas_polbraeco,586120/64-dos-brasileiros-entendem-que-o-aborto-e-decisao-exclusiva-da-mulhe.shtml 
Segundo os dados das CDD, $64 \%$ das pessoas defendem que o direito de decidir sobre a interrupção da gravidez é da mulher. O número mostra que a maioria da população acredita na escolha individual da mulher quando esta diz respeito à própria gravidez. Ainda assim, o aborto segue sendo considerado como crime no Brasil, exceto nos casos de anencefalia, estupro ou gestação com risco de vida para a gestante - em risco atualmente com a tramitação da PEC 181. Essa pesquisa também nos possibilita compreender a narrativa contida na Figura 4. Mesmo sendo católica, a autora da postagem não é contrária à legalização do aborto, ainda que o catolicismo se posicione radicalmente contra.

Um dos aspectos que mais chamaram a nossa atenção foi que nas buscas utilizando a palavra-chave "gênero" o termo apareceu associado à laicidade de forma pejorativa, ou seja, como se o Estado laico promovesse a chamada "ideologia de gênero".

Aqui, vale a pena discutir brevemente o que se entende por "ideologia de gênero". Do ponto de vista dos estudos feministas, podemos dizer que a expressão se refere a um novo dispositivo retórico que busca estabelecer que as normas sexuais não são nem históricas nem políticas. Na prática, esse dispositivo vem sendo propagado em diversos países, estabelecendo um "pânico moral" entre as pessoas, uma vez que as diferenciações das identidades de gênero são profundamente entranhadas na sociedade (Sara GARBAGNOLI, 2016).

Na América Latina, um dos principais propagadores da "ideologia de gênero" é o argentino Jorge Scala (2015), autor do livro ideologia de gênero: o neototalitarismo e a morte da família. Em entrevista concedida ao Portal Zenit, ele respondeu à pergunta "o que é a ideologia de gênero?" da seguinte forma:

Seu fundamento principal e falso é este: o sexo seria o aspecto biológico do ser humano, e o gênero seria a construção social ou cultural do sexo. Ou seja, que cada um seria absolutamente livre, sem condicionamento algum, nem sequer o biológico-, para determinar seu próprio gênero, dando-lhe o conteúdo que quiser e mudando de gênero quantas vezes quiser (Jorge SCALA 2015).

Nessa definição, Jorge Scala (2015) afirma que somente uma lavagem cerebral global poderia incutir nas pessoas a chamada "ideologia 
de gênero". Sobre esta suposta "lavagem cerebral", Judith Butler (2017) discorreu brevemente após sua conturbada vinda ao Brasil. Segundo a filósofa: "uma ideologia é entendida como um ponto de vista que é tanto ilusório quanto dogmático, algo que 'tomou conta' do pensamento das pessoas de uma maneira acrítica" (Judith BUTLER 2017). Nesse sentido, sua teoria da performatividade de gênero não pode ser entendida como ideológica, pois não é acrítica. Esse posicionamento, no entanto, não parece suficiente para que a direita conservadora e cristã interrompa sua ofensiva contra os estudos de gênero.

Ademais, na Figura 1, a resposta ao tweet inicial cita Guilherme Boulos, um dos líderes do Movimento dos Trabalhadores Sem Teto (MTST), e Jean Wyllys, deputado eleito pelo PSOL. Segundo a postagem, ambos são intelectuais que de "tanto respeitar a laicidade" falam "até em diversidade de gênero". Implicitamente, a ideia de um Estado laico é vista como um problema, pois permite que a esquerda defenda a "diversidade de gênero", muito possivelmente identificada com a "ideologia de gênero" pelo autor da postagem. Sugere, portanto, que se o Estado fosse cristão, seria possível impor a todas as pessoas a linearidade e correspondência entre sexo, identidade de gênero e orientação sexual. O tweet seguinte também utiliza a mesma relação:

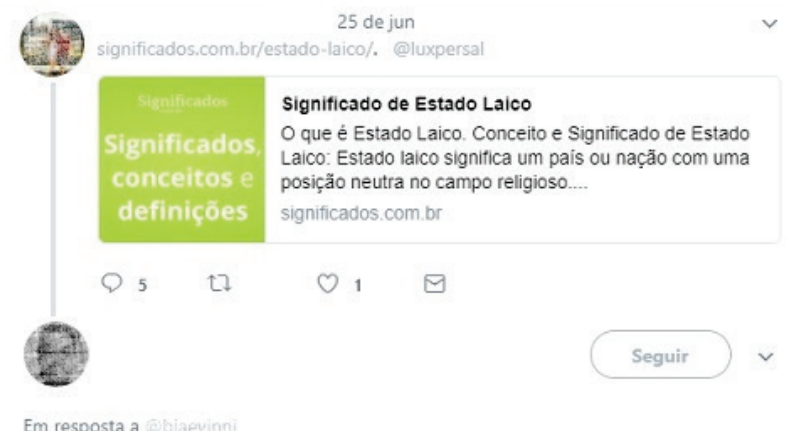

Graças a laicidade d Estado temos hj a ideologia de gênero e o comumismo derretendo o cérebro e a consciência d nossa gente...

$11: 47$ - 25 de jun de 2017

Figura 6. Laicidade, ideologia de gênero e comunismo 
O que os/as participantes desse debate não têm em mente é que o Estado tem como objetivo garantir a todos o direito de culto e a proteção das manifestações religiosas individuais. De igual modo, há um entendimento geral de que falar de gênero, sobretudo com jovens e crianças, é um meio de incutir certa "ideologia" na população.

A Figura 7 é outra postagem que estabelece a relação entre Estado laico e ideologia de gênero, mas, dessa vez, tratando a laicidade como simples liberdade religiosa:

\section{7 de mai \\ A Ideologia de Gênero fere a minha LAICIDADE como cristão. \\ Sou CONTRA e tenho embasamento para combater a este mal.}

Q $\quad$ ᄂ

Figura 7. "Ideologia de gênero fere a minha laicidade".

O autor do tweet usou a laicidade de uma forma bem particular, entendendo-a como o seu direito de ser e pensar como cristão. Nesse sentido, ele afirma que a ideologia de gênero, provavelmente em termos semelhantes aos usados por Jorge Scala, fere sua religiosidade.

Ainda sobre a suposta "ideologia de gênero", encontramos um relato interessante, e documentado, sobre o processo de retirada dos debates de gênero nas escolas da cidade de Cascavel, no Paraná:

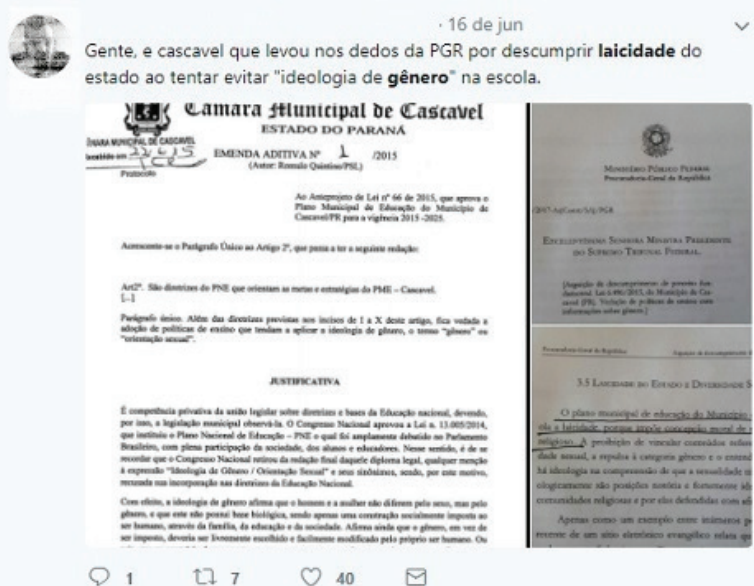

Figura 8. Descumprimento da laicidade em Cascavel, PR 
Nos documentos incluídos na postagem, é possível ver que a Câmara Municipal de Cascavel retirou do seu Plano de Ensino, em 2015, toda a discussão sobre gênero. Em 2017, o Procurador Geral da República (PGR), Rodrigo Janot, incluiu a cidade na lista de municípios que têm leis inconstitucionais por descumprir o princípio da laicidade. No documento redigido pela PGR, lemos:

o plano de educação do Município de Cascavel viola a laicidade, porque impõe concepção moral de marcado fundo religioso. A proibição de vincular conteúdos referentes à diversidade sexual, a repulsa à categoria gênero e o entendimento de que há ideologia na compreensão de que a sexualidade não se define biologicamente são posições notórias e fortemente identificadas com comunidades religiosas e por elas defendidas com afinco.

O relatório explicita como a questão da "ideologia de gênero" tem origem nas comunidades religiosas, que enxergam na desconstrução das diferenças, sejam elas biológicas ou culturais, entre homens e mulheres, uma ameaça aos valores cristãos. Nesse caso, entendemos que a laicidade, ainda que tenha como base a proteção da liberdade religiosa, não pode ser usada como escudo. O posicionamento da PGR em defesa do Estado laico, contudo, não é padrão na política nacional. O que acontece com enorme frequência é a aprovação de projetos, leis, planos e diretrizes que não seguem a separação efetiva entre religiões e Estado. Por isso, defendemos aqui que mais importante que usar o argumento político de que o nosso Estado é constitucionalmente laico, é adotar estratégias para que ele se torne, inclusive legalmente, efetivamente não comprometido com pensamentos religiosos.

\section{CONSIDERAÇÕES FINAIS}

Trabalhar com o tema da laicidade no atual momento brasileiro não é apenas complexo, é também inferir em propostas de argumentos legais, dependendo do assunto. Todos os dias surgem novas notícias que ferem o princípio do Estado laico. Só na última semana o prefeito do Rio de Janeiro realizou um censo religioso entre os policiais da cidade com o polêmico objetivo de criar um serviço de assistência religiosa aos 
militares $(G 1,2017)$. Além disso, um pastor, no Espírito Santo, entrou numa creche para retirar uma boneca negra, uma abayomi da tradição africana, exposta num cartaz, sob a alegação de que ela era um símbolo de macumba (Raquel LOPES, 2017).

Esses exemplos mostram que há uma tensão constante entre religiões e as demais esferas da vida pública. De um lado, temos o Estado, que constitucionalmente deve se manter longe dos princípios religiosos em uma democracia; do outro, as religiões que disputam um espaço legitimador na sociedade. Nesse cabo de guerra, como ficam as questões relacionadas ao gênero?

Partimos de uma intuição forte de que mulheres, lésbicas, trans, travestis e todas as pessoas que não correspondem ao padrão esperado do indivíduo de direitos (homem, cis, branco, heterossexual, cristão e detentor do poder de consumo) são mais prejudicadas por um Estado que não consegue se manter independente das ingerências religiosas. Essa intuição não necessariamente foi provada pelos debates teóricos ou pelo campo, mas fica evidente para nós que é fundamental pensar o conceito de laicidade sob uma perspectiva de gênero.

Afinal, há um imbricamento explícito entre o cristianismo, a construção histórica das identidades e atribuições de gênero e o sistema de opressão de mulheres. Parece-nos que uma linha conecta o catolicismo que queimou as feiticeiras e os fervorosos cristãos que hoje combatem a ideologia de gênero. Se esta hipótese está correta, falar de laicidade, de forma realmente comprometida, exige um retorno ao debate sobre a história das mulheres e das relações de gênero. Tentamos, neste artigo, caminhar em direção a esse fim, mostrando tanto as vinculações teóricas quanto os discursos atuais que alinhavam gênero e laicidade no Brasil, acreditando que este não é apenas um trabalho acadêmico, mas também um trabalho político.

\section{REFERÊNCIAS}

BICALHO, Elizabete. A nódoa da misoginia na naturalização da violência de gênero: Mulheres Pentecostais e Carismáticas. Dissertação (Mestrado em Ciências Humanas) - Pontifícia Universidade Católica de Goiás, Goiânia, 2001.

BLANCARTE, Roberto J.. ¿Cómo podemos medir la laicidad? Estudios Sociológicos, vol. XXX, n. 88, pp. 233-247, 2012. 
BLANCARTE, Roberto. El por qué de un Estado laico. Memoria de Ponencias I Foro Centroamericano de Libertades Laicas. Asociación Colectiva por el Derecho a Decidir, 1 ed. San José: Colectiva por el Derecho a Decidir, pp. 12-35, 2008.

BUTLER, Judith. Cuerpos que importan. Sobre los límites materiales y discursivos del "sexo". Buenos Aires: Paidós, 2002.

BUTLER, Judith. Problemas de gênero: feminismo e subversão da identidade. Rio de Janeiro: Civilização Brasileira, 2003.

BUTLER, Judith. Judith Butler escreve sobre sua teoria de gênero e o ataque sofrido no Brasil. Folha de S. Paulo, 2017. Disponível em: http://folha.uol.com.br/ ilustrissima/2017/11/1936103-judith-butler-escreve-sobre-o-fantasma-do-genero-e-o-ataque-sofrido-no-brasil.shtml (acesso em 29/11/2017).

CATROGA, Fernando. Entre deuses e césares. Secularização, laicidade e religião civil: uma perspectiva histórica. Coimbra: Edições Almedina, 2006.

ESCÓSSIA, Liliana da; KASTRUP, Virgínia; PASSOS, Eduardo (Orgs.). Pistas do método da cartografia: Pesquisa-intervenção e produção de subjetividade. Porto Alegre: Sulina, 2012.

G1. Prefeitura do Rio faz censo religioso na Guarda Municipal, 09/08/2017. Disponível em: https://g1.globo.com/rio-de-janeiro/noticia/prefeitura-do-rio-faz-censo-religioso-na-guarda-municipal.ghtml (acesso em 03/11/2018).

GARBAGNOLI, Sara. Against the Heresy of Immanence: Vatican's 'Gender' as a New Rhetorical Device Against the Denaturalization of the Sexual Order. Religion and Gender 6(2), 264-272, 2016.

GIUMBELLI, Emerson. O fim da religião: dilemas da liberdade religiosa no Brasil e na França. São Paulo: Attar Editorial, 2002.

GONÇALVES, Tamara Amoroso; LAPA, Thais de Souza. Aborto e religião nos tribunais brasileiros. Coordenação de Tamara Amoroso Gonçalves. São Paulo: Instituto para a Promoção da Equidade, 2008.

LAQUEUR, Thomas. Inventando o sexo. Corpo e gênero dos gregos a Freud. Rio de Janeiro: Relume Dumará, 2001.

LOPES, Raquel. Pastor retira boneca afro em creche de Vitória e diz ser "símbolo de macumba”. G1, 11/08/2017. Disponível em: https://g1.globo.com/espirito-santo/noticia/ pastor-retira-boneca-afro-em-creche-de-vitoria-e-diz-ser-simbolo-de-macumba.ghtml (acesso em 03/11/2018).

NICHOLSON, Linda. Interpretando o gênero. Estudos Feministas. Florianópolis, vol.8, n.2, p. 09-41, Florianópolis: UFSC, 2009. Disponível em: https://periodicos.ufsc.br/index. php/ref/article/view/11917. Acesso em: 29 nov. 2017.

RANKE-HEINEMANN, Uta. 1996. Eunucos pelo reino de Deus. Mulheres, sexualidade e a Igreja Católica. Rio de Janeiro: Editora Rosa dos Ventos, 1996. 
RANQUETAT JÚNIOR, César A. Laicidade, Laicismo e Secularização: definindo e esclarecendo conceitos. Revista Sociais e Humanas, v. 21, n. 1, p. 1-14, 2008.. Disponível em: https://periodicos.ufsm.br/sociaisehumanas/article/view/773. Acesso em: 29 nov. 2017. ROSADO-NUNES, Maria José. As complexas relações entre religião e gênero. In: Nunes, Maria José Rosado (org.). Gênero, feminismo e religião: sobre um campo em construção. Rio de Janeiro: Garamond, 2015.

SCALA, Jorge. Ideologia de gênero e a morte da família. Entrevista concedida ao Portal Zenit, 31 jan. 2015. Disponível em: https://pt.zenit.org/articles/ideologia-de-genero-neototalitarismo-e-a-morte-da-fami-lia/. Acesso em 29 de nov. 2017.

SCOTT, Joan. Gênero: uma categoria útil de análise histórica. Educação e Realidade, Porto Alegre, 16(2). Jul/Dez, 1990.

VIANNA, Túlio. Um outro Direito. Rio de Janeiro: Lumen Juris, 2014.

Submetido em: 26-9-2018

Aceito em: 7-11-2018 